\title{
First Year Experience Course: Insights From The First Two Years
}

Sheri L. Erickson, Minnesota State University Moorhead, USA Mary F. Stone, Minnesota State University Moorhead, USA

\begin{abstract}
Retention rates of students in a business school Freshman Year Experience (FYE) course were compared to overall University retention rates for two successive years. Slightly higher retention was experienced by the business FYE students than for the University overall. Student responses to exit survey questions were compared to retention activity to assess any potential relationships. Contrary to existing theoretical models, no significant correlations existed between measures of academic skill building and retention, and between student connectedness and retention. Significant correlation did exist between student academic expectations and intention to return.
\end{abstract}

Keywords: Freshman Year Experience; Student Retention; Business Students

\section{INTRODUCTION}

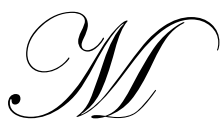

any business schools have implemented courses to help freshman successfully transition into college life and introduce them to various business majors. These courses vary in delivery type (face-to-face versus online), course length (one versus several credit hours), and topical coverage (introduction to business courses, socialization into college life, and skills for academic success). The desired outcomes of offering these courses are to provide students with the skills they need to be productive and successful students and to improve university and business school retention rates.

One medium-sized Midwestern university has utilized a three-pronged approach by offering three, onecredit courses that freshman take in the first semester of college. One course is a general Freshman Year Experience (FYE) course that focuses on general academic and socialization success; another course offers exposure to various business disciplines and opportunities and topics unique to business majors; and a third course contains material about alcohol awareness. This study follows students who were initially enrolled in business FYE courses from two years prior to determine whether this unique approach was successful in retaining those students into their second year of college at the university. Attrition rates for students enrolled in FYE the second year it was offered were also assessed to determine if those rates had changed from the prior year. In addition, survey responses were analyzed to determine what factors were significantly correlated with retention from year one to year two.

\section{PREVIOUS RESEARCH}

Much has been written regarding student retention and the factors that influence retention. More than onehalf of students who drop out of college do so in their first year (Cox, Schmitt, Bobrowski, and Graham, 2005). Several variables have been linked to retention, including high school GPA (Cox, et al, 2005; Murtaugh, Burns, and Schuster,1999; and DeBernard, Spielmans, and Julka, 2004), first semester college GPA (Mangum, Baugher, Winch and Varanelli, 2005), financial resources (Cox, et al, 2005; Mangum, et al. 2005), residency (Murtaugh, et al, 1999), unmet expectations (Braxton, Vesper, and Hossler, 1995), age of student (Murtaugh, et al, 1999), and enrollment in a First Year Experience (FYE) course (Cox, et al, 2005; Murtaugh, et al, 1999).

Models to explain the value of a First Year Experience course for improving retention fall into two main camps (Ryan and Glenn, 2004). In one model, based on Tinto's (1975) interactionalist model, an FYE course increases a student's feeling of academic and social integration into the university, thus increasing his or her 
commitment to the university, leading to an increase in retention. The second explanation for FYE's positive effect on retention is that the freshman year experience course increases a student's set of skills and strategies to academically succeed, thereby improving student performance and college GPA, leading to increased retention. Ryan and Glenn (2004) find that one year retention rates are higher for students in a strategy-based (skill building) FYE course than for students in a socialization-focused group (similar to Tinto's model). The strategy based FYE students also outperformed, as measured by retention rates, students not enrolled in any freshmen introduction course.

Many of the FYE courses described in the literature have attempted to address both frameworks (Damminger, Potter, \& Pritchard, 2009). Courses often include discussions, reading assignments, and guest speakers which address both the strategies needed for academic success, and the needed information to socialize and integrate the new students into the university. This dual purpose is often seen both in freshmen seminars that are offered at the university wide level, and in seminars offered within specific colleges and schools, including schools of business.

Cox, et al (2005) identify four factors that are important in the promotion of academic success and retention. These are: 1) early and frequent interaction with faculty, staff, and peers 2) clearly communicated academic expectations and requirements; 3) learning opportunities that increase involvement with other students; and 4) academic, social, and personal support. All of these are important components of a freshman year experience course aimed at business students. First Year Experience courses or freshmen mentoring programs have been utilized at many Universities, including those mentioned in Weber, Stone, and Erickson (2009) Heirdsfield, Walker, and Walsh (2008), Jamelske (2009), and Reaves and Marchant (2010). These FYE courses differ in their unique layout of the course, the degree to which the course promotes the previously mentioned retention factors (Cox et al 2005), and the extent to which student retention is enhanced as a result of the FYE courses.

Other universities have utilized a specific Business FYE course and these courses have been implemented as a way to encourage interactions between freshmen business majors and business school faculty and future employers early in the student's academic career (Erickson, Stone, and Weber, 2010; Belcher, 2010; Crutchfield and Eveland, 2008; Chonko and Roberts, 1996; and Lamb, Lee, and Vinton, 1997). Both Erickson et al (2010) and Crutchfield and Eveland (2008) collected survey data from students to assess the effects of their FYE courses. Among the data collected were student responses concerning perceived connectedness to other students, faculty, and the University, amount of academic skill building, as well as the students' intent to stay in the business school.

While data concerning student perceptions of FYE effectiveness and intentions to stay in the business school are interesting, the more useful and urgent results for the University are increased student retention. FYE courses have been shown to enhance retention in some studies (Reaves and Marchant 2010), while having no significant effects in other studies (Barton and Donahue 2009, Hendel 2007, Jamelske 2009, Strayhorn 2009). Because of the nondefinitive relationship between FYE courses and retention, this current paper will discuss the results of a Freshman Year Experience course at a medium sized Midwestern university by examining student retention for students who took part in a FYE course sequence designed for business majors. Retention data from 2008 and 2009 is compared to the University rates to determine whether this particular three-pronged approach to FYE appeared to improve student retention. In addition, survey data is analyzed to determine whether there are significant correlations between survey responses and one year retention.

\section{RESEARCH QUESTIONS}

Student attrition is costly for both the university and the student. Universities lose tuition dollars and the cost of the time and energy invested in recruiting, teaching, counseling, housing, and record keeping for the students makes attrition extremely expensive. Students lose not only their immediate out of pocket expenses, but also future earnings potential as well as psychological health (Mangum, Baugher, Winch, and Varanelli, 2005). The high cost of attrition for all parties propels the need for increased retention rates within colleges and universities. These motivations have led many universities to implement First Year Experience courses as a means to improve retention rates of students. After several years of using a FYE course at one medium sized Midwestern university, the following research questions need to be addressed: 
RQ1: "What percentage of students enrolled in business FYE were enrolled one year later at the University?"

RQ2: “Is there a difference in retention rates from 2008 and 2009 for freshman taking FYE?"

RQ3: "Are students who indicate an intention to return likely to do so?"

RQ4: "Are any other survey questions significantly correlated with one-year retention?"

\section{RESEARCH DESIGN AND RESULTS}

Students enrolled in FYE fall 2008 and fall 2009 were surveyed at the end of the semester to determine whether FYE provided benefits by asking students to rate whether the course helped with time management, the students' ability to meet new people and connect with faculty, whether it provided information to enhance their understanding of business, and if the course encouraged student collaboration. In addition, the students were asked whether they planned to return to the university and whether they would recommend the business school to other prospective students. A sample survey is provided in Appendix A.

Those students who took the three-pronged Business FYE course in fall 2008 and fall 2009 were tracked in December 2010 after fall grades were posted. The most recent semester of enrollment, cumulative GPA, and current academic major were recorded. In addition, average ratings were calculated for each survey question.

Research question 1 asks what the retention rates were for each FYE semester and how those rates compared to the University. Retention was calculated each semester for students who took the business FYE courses in fall 2008 and fall 2009. The FYE student results were compared to University retention rates for all freshman students entering the University. For those freshmen who took business FYE in 2008, 88.2\% were enrolled after the first semester, $69.1 \%$ came back for their second year, and $55.9 \%$ returned for their $3^{\text {rd }}$ year of school. The retention rates for the University were slightly lower, with $66.6 \%$ of freshman entering fall 2008 returning a year later and $53.5 \%$ returning in two years. These retention rates provide evidence, as indicated in other studies (Cox, Schmitt, Bobrowski, and Graham, 2005), that retention from year 1 to year 2 seems to be key as indicated by the fact that the largest attrition rate occurred during this time period.

Research question 2 asks whether retention rates for FYE students were higher in 2009 than in 2008 . The retention rates for students who took the FYE courses in fall 2009 were slightly higher than rates for students who took FYE in fall 2008, with 39 out of 52 (75\%) students returning for their second year of school at the University. The University one-year retention rate for this entering freshman class was also higher than the previous year, but still lower than the business FYE students at 67.4\%. The higher retention rates for freshman entering in 2009 (as compared to 2008) was somewhat surprising because average scores to the survey questions were, in general, slightly less positive than average scores from 2008. Table 1 shows these scores.

Table 1: Average Scores for Survey Questions

\begin{tabular}{|c|c|c|c|}
\hline $\begin{array}{l}\text { Section A Questions } \\
\text { Likert Scale of } 1=\text { Not at all to } 7=\text { Significantly }\end{array}$ & Mean 2008 & Mean 2009 & $+/-*$ \\
\hline 1. Course increased degree of completing homework on time & 3.88 & 3.79 & - \\
\hline 2. Course improved priority-setting abilities. & 4.12 & 4.00 & - \\
\hline 3. Course improved ability to meet new people. & 3.74 & 3.76 & + \\
\hline 4. Course provided encouragement for students to work together. & 3.90 & 3.71 & - \\
\hline 5. Degree of acceptance at this university. & 5.65 & 5.59 & - \\
\hline 6. Ease of making new friends at this university. & 5.26 & 5.18 & - \\
\hline 7. Plan to return to this university next year. & 6.01 & 6.06 & + \\
\hline 8. Plan to transfer to another college/university next year. & 2.09 & 1.96 & + \\
\hline 9. Plan to not enroll in any college/university next year. & 1.06 & 1.02 & + \\
\hline 10. Would recommend this university to a friend. & 5.75 & 5.73 & - \\
\hline
\end{tabular}




\begin{tabular}{|c|c|c|c|}
\hline $\begin{array}{l}\text { Section B Questions } \\
\text { Likert Scale of } 1=\text { Strongly disagree to } 7=\text { Strongly agree }\end{array}$ & Mean & & $+/-$ \\
\hline 1. Course helped me develop connections with students. & 4.13 & 4.16 & + \\
\hline 2. Course helped me develop connections with professors. & 4.22 & 4.18 & - \\
\hline 3. Course helped me understand the business program. & 5.69 & 5.74 & + \\
\hline 4. Course helped me develop a general knowledge of business. & 5.74 & 5.74 & \\
\hline 5. Course helped me adjust to college life. & 4.09 & 4.00 & - \\
\hline 6. Course provided resources to improve academic success. & 4.43 & 4.39 & - \\
\hline 7. I am satisfied with business FYE. & 4.63 & 4.67 & + \\
\hline 8. I intend to complete my degree at this university. & 5.76 & 5.80 & + \\
\hline 9. I intend to stay in the School of Business at this university. & 5.26 & 5.08 & - \\
\hline 10. I like the curriculum better that other business school curriculum. & 4.48 & 4.39 & - \\
\hline
\end{tabular}

+/- indicates whether or not students' answers reflected a positive difference from 2008 to 2009 .

Research question \#3 asks whether FYE students who indicated that they intended to return to the University the following year did so. From the post survey, section A question numbers 7and 8, along with section B question numbers 8 and 9 were designed to measure student intent to return to the University. These questions were found reliable at an alpha of .9044 for 2008 and .9220 for 2009. This intention to return scale was compared to whether the students actually returned to the University the following year using Pearson product-moment correlation coefficient. For 2009 there was a relatively strong, positive correlation between the two variables $(\mathrm{r}=.496, \mathrm{n}=52, \mathrm{p}<.001)$, with an indication of intent to return with actually returning. There was no significant correlation for 2008. In addition, all other questions on the surveys were tested for correlation with returning the following year and no significant correlation was found.

An examination of the correlation of the individual survey questions with each other yields several interesting layers of relationships. Pearson product moment correlations were calculated for each survey item as well as actual retention measures. Other than the intent to return scale, the only item that is significantly correlated with actual retention each year is question 10 from section B in the 2009 class survey which measures satisfaction with the business school curriculum, in which we found that those who felt the business school curriculum was better that other business schools was compared to whether the students actually returned to the University the following year. Using Pearson product-moment correlation coefficient, for 2009 there was a slight, positive correlation between the two variables $(r=.277, n=51, p<.005)$, with an indication of satisfaction with the curriculum with actually returning.

We then questioned what was correlated with intent to return. We found that the intent to return items were obviously correlated with each other, but also, in 2008, each intent to return survey question was also correlated with question 6 from section A, which measured the student's perceptions of their ability to make new friends. For 2008 there was a relatively strong, positive correlation between the variable of perceived ability to make new friends and the intent to return scale $(\mathrm{r}=.43, \mathrm{n}=68, \mathrm{p}<.001)$. Also, stemming from the two models posited by Ryan and Glenn (2004), we looked at any relationships between academic skill-building survey questions and intent to return, and between feelings of connectedness questions and intent to return. Section A questions 1 and 2, and Section B questions 5 and 6 measure academic skill building. Section A questions 3-6, and Section B questions 1-2 measure connectedness. Section B questions 3-4 measure alignment of expectations and academic requirements for students in the business program. Reliability for each scale was tested in 2008 and 2009, indicating all scales, except for connectedness, were reliable (Table 2):

Except for the relationship mentioned earlier between intent to return and making friends, no correlations existed between skill building or connectedness and intent to return. The expectation alignment scale was positively correlated with the skill building scale $(\mathrm{r}=.373, \mathrm{p}<.01, \mathrm{n}=68$ for 2008 , and $(\mathrm{r}=.415, \mathrm{p}<.01, \mathrm{n}=52)$ for 2009, indicating a relationship between these two constructs. In addition, the intent to return scale was positively correlated with the expectation scale $(\mathrm{r}=.458, \mathrm{p}<.01, \mathrm{n}=52)$ in 2009. Somehow, those relationships do not correspond to an increased intention to return, nor to actual retention. 
Table 2: Survey Question Categories

\begin{tabular}{|l|c|c|}
\hline Topics Addressed by Survey Questions & Section A & Section B \\
\hline Intent to Return & Questions 7, 8 & \\
Alpha 2008 $=.9044$ & & Questions 5, 6 \\
Alpha 2009=.9220 & Questions 1, 2, \\
\hline Skill building & & \\
Alpha 2008=.8117 & & Questions 1,2 \\
Alpha 2009=.8110 & Questions 3, 4, 5, 6 & \\
\hline Connectedness & & Questions 3, 4 \\
Alpha 2008=.6462 & & \\
Alpha 2009=.4975 & & \\
\hline Expectations & & \\
Alpha 2008=.7986 & & \\
Alpha 2009-.9164 & & \\
\hline
\end{tabular}

\section{CONCLUSION}

The current study examined one specific University's assessment of its FYE program, currently in its third year; therefore, generalizability of any results is limited. Similar to other case studies, our retention rates for the FYE course were better than overall University rates, but not significantly so. We expanded the research stream by examining the results of a student survey given at the exit of the FYE course. We found significant correlation between students' indication of their intent to return and their actual return the following year. These results indicate that efforts to retain students are important in the first semester of their college careers. Students who indicate they plan to return the following year are likely to do so and are not at high risk of attrition. No other survey results were significantly correlated with the student's actual retention, lending no support for Ryan and Glenn (2004) and Tinto's (1975) models of the determinants of retention. The correlations between the scales for skill building, connectedness, intent to return, and expectation alignment show some relationship between these four constructs. While students' actual retention is related to their reported intent, we are still left questioning how to enhance their intent to return. Retention efforts must be directed toward those who have determined almost a full academic year in advance that they will not return. Perhaps a survey given mid-semester would red flag those students at risk for attrition. In addition to asking students about their future college plans, the survey should ask more specific questions about the students' reasons for not attending the following year. Appropriate intervention could help students to change their future plans.

Our low correlation between survey items and retention might be because connectedness and skill building do not enhance retention, as discussed previously. Alternately, connectedness and skill building might enhance retention, but perhaps this specific program is not designed well enough to promote these two factors. This could be addressed by future refinements of the FYE course at the University. Thirdly, the effect of expectations could override any effect of connectedness and skill building. Part of our FYE course was designed to give students an understanding of future business career paths and of the expectations of the business curriculum at the University. College standards had recently been tightened and those standards were communicated to the students. Perhaps the communication of the higher standards gave some students reason to question their major and even change their major, which would result in the lack of a boost in retention after the implementation of the FYE course.

While the correlation of expectations to actual return was not significant, the correlation of expectations to intention to return was significant $(\mathrm{r}=.458, \mathrm{n}=52, \mathrm{p}<.001)$. This result supports Cox et al's (2005) proposition that clearly communicated academic expectations and requirements is one of the four necessary factors which promotes student academic success and retention. Any negative effect on retention caused by a tightening of the matriculation standards are expected to be short lived, as a more stringent curriculum attracts higher qualified students who are committed to the challenge of a rigorous program. We anticipate this is the case. A replication of this research in the future would shed additional light on the determinants of retention. 


\section{AUTHOR INFORMATION}

Sheri L. Erickson, Ph.D., is Professor of Accounting and Co-Chair, School of Business, Minnesota State University Moorhead. She earned her Ph.D. from North Dakota State University. Her research interests include student retention and leadership, and organizational crisis communication and strategy, particularly in the area of corporate reporting. She has published research in Issues in Accounting Education, Journal of Organizational Culture, Communications and Conflict, Journal of Business Communication, Accounting Information Systems Educators Journal, Journal of Forensic and Investigative Accounting, Business Education Innovation Journal, Academy of Accounting and Financial Studies Journal, Academy of Banking Studies Journal, and Advances in Accounting, Finance, and Economics. Minnesota State University Moorhead, $11047^{\text {th }}$ Ave S., Moorhead, MN 56563; E-mail: erickson@mnstate.edu; Phone: 218-477-4073.

Mary Stone, Ph.D., is Assistant Professor of Accounting at Minnesota State University Moorhead. She earned her Ph.D. from Virginia Tech University. She teaches financial and managerial accounting, as well as cost accounting and advanced accounting. Her research interests include business education, ethics in business decision making, managerial and behavioral issues. She has published research in Issues in Accounting Education, Journal of Organizational Culture, Communications and Conflict, Business Education Innovation Journal, and Accounting Instructors' Report. Minnesota State University Moorhead, $11047^{\text {th }}$ Ave S., Moorhead, MN 56563; E-mail: stone@mnstate.edu. Phone: 218-477-4660. Corresponding author.

\section{REFERENCES}

1. Barton, A. \& Donahue, C. (2009). Multiple assessments of a first-year seminar pilot. The Journal of General Education, 58(4), 259-278.

2. Belcher, L. J. (2010). Freshman integration and retention in the business school: The long term effectiveness of a dedicated first year business freshman experience course. Business Education Innovation Journal, 2(1), 27-34.

3. Braxton, J.,Vesper, N., \& Hossler, D. (1995). Expectations for college and student persistence. Research in Higher Education, 36(5), 595-612.

4. Chonko, L. \& Roberts, J. (1996). An innovative introduction to business course: Marketing the skills that marketing majors (and others) as business majors will need for success. Marketing Education Review, 6(3), 53-71.

5. Cox, P., Schmitt, E., Bobrowski, P., \& Graham, G. (2005). Enhancing the first-year experience for business students: Student retention and academic success. Journal of Behavioral and Applied Management, 7(1), 40-68.

6. Crutchfield, T. \& Eveland, V. (2008). Rethinking the first year for and increasing retention of business school students. Journal of the Academy of Business Education, 9, Summer, 1-16.

7. Damminger, J.K., Potter, G.C., \& Pritchard, R.E. (2009). Adding value to the first-year experience: Embedding self and major exploration in the college of business curriculum. American Journal of Business Education, 2(3), 49-56.

8. DeBernard, M., Spielmans, G, \& Julka, D. (2004). Predictors of academic achievement and retention among college freshmen: A longitudinal study. College Student Journal, 38(1), 66-80.

9. Erickson, S., Stone, M., \& Weber, M. (2010). Enriching business students' first year experience: A unique approach. Business Education Innovation Journal, 2(1), 35-43.

10. Heirdsfield, A. M., Walker, S., \& Walsh, K.M. (2008). Enhancing the first year experience - longitudinal perspectives on a peer mentoring scheme. In Proceedings Australian Association for Research in Education. Research impacts: Proving or improving, Fremantle, Australia.

11. Hendel, D. D. (2007). Efficacy of participating in a first-year seminar on student satisfaction and retention. Journal of College Student Retention: Research, Theory and Practice, 8(4), 413-423.

12. Jamelske, E. (2009). Measuring the impact of a university first-year experience program on student GPA and retention. Higher Education, 57(3), 373-391.

13. Lamb, C., Lee, J. \& Vinton, K.(1997). Developing a freshman seminar: Challenges and opportunities. Journal of Management Education, 21(1), 27-43. 
14. Mangum, W., Baugher, D., Winch, J., \& Varanelli, A. (2005). Longitudinal study of student dropout from a business school. Journal of Education for Business, 80(4), 218-221.

15. Murtaugh, P., Burns, L., \& Schuster, J. (1999). Predicting the retention of university students. Research in Higher Education, 40(3), 355-371.

16. Reaves, D. W. \& Marchant, M.A. (2010). Student retention: Impacts of an agricultural economics first year seminar course. Selected Paper prepared for presentation at the Southern Agricultural Economics Association Annual Meeting Orlando, FL, February 6-9, 2010.

http://ageconsearch.umn.edu/bitstream/56476/2/2010-SAEA_Paper_Reaves_Marchant.pdf.

17. Ryan, M. \& Glenn, P. (2004). What do first year students need most: Learning strategies instruction or academic socialization? Journal of College Reading and Learning, 34(2), 4-28.

18. Strayhorn, T. L. (2009). An examination of the impact of first-year seminars on correlates of college student retention. Journal of the First Year Experience and Students in Transition, 21(1), 9-27.

19. Tinto, V. (1975). Dropout from higher education: A theoretical synthesis of recent research. Review of Educational Research, 45(1), 89-125.

20. Weber, M., Stone, M., \& Erickson, S. (2009). Accounting students and the first year experience course. Accounting Instructors Report, Summer 2009.

http://college.cengage.com/accounting/resources/instructors/air/summer_2009/index.html. 


\section{APPENDIX A}

\section{END OF SEMESTER SURVEY FOR BUSINESS FYE}

Please answer the following questions regarding the Business FYE course.

Name:

ID:

Section A: Please circle your response to the first 10 questions using the following scale:

$1=$ not at all, $4=$ somewhat, $7=$ significantly

1. Taking this class increased the degree to which I completed homework assignments on time.

$\begin{array}{lllllll}1 & 2 & 3 & 4 & 5 & 6 & 7\end{array}$

2. Taking this class improved the degree to which I set my priorities so I can accomplish what is most important to me.

$\begin{array}{llllllll}1 & 2 & 3 & 4 & 5 & 6 & 7\end{array}$

3. Taking this class improved my ability to meet new people.

$\begin{array}{llllllll}1 & 2 & 3 & 4 & 5 & 6 & 7\end{array}$

4. To what degree did this course include encouragement for students to work together?

$\begin{array}{llllllll}1 & 2 & 3 & 4 & 5 & 6 & 7\end{array}$

5. To what degree are you accepted by students at this university?

$\begin{array}{llllllll}1 & 2 & 3 & 4 & 5 & 6 & 7\end{array}$

6. To what degree is it easy for you to make new friends at this university?
$\begin{array}{llllllll}1 & 2 & 3 & 4 & 5 & 6 & 7\end{array}$

7. For the next academic year to what degree do you plan to return to this university?

$\begin{array}{llllllll}1 & 2 & 3 & 4 & 5 & 6 & 7\end{array}$

8. For the next academic year, to what degree do you plan to transfer to another college/university?

$\begin{array}{lllllll}1 & 2 & 3 & 4 & 5 & 6 & 7\end{array}$

9. For the next academic year to what degree do you plan NOT to enroll in any college/university?

$\begin{array}{llllllll}1 & 2 & 3 & 4 & 5 & 6 & 7\end{array}$

10. To what degree would you recommend this university to a friend?

$\begin{array}{llllllll}1 & 2 & 3 & 4 & 5 & 6 & 7\end{array}$


Section B: Please circle your response to the following 10 questions using the following scale:

$$
1=\text { strongly disagree, } 7 \text { = strongly agree }
$$

Business FYE has helped me to:
1. Develop connections with

$$
\text { Strongly }
$$
Strongly
Disagree
Agree

other students

$\begin{array}{llllllll}1 & 2 & 3 & 4 & 5 & 6 & 7\end{array}$

2. Develop connections with professors

$\begin{array}{llllllll}1 & 2 & 3 & 4 & 5 & 6 & 7\end{array}$

3. Understand the business program

$\begin{array}{lllllll}1 & 2 & 3 & 4 & 5 & 6 & 7\end{array}$

4. Develop a general knowledge of business

1

2

5. Adjust to college life

1

2

$\begin{array}{lllll}3 & 4 & 5 & 6 & 7 \\ 3 & 4 & 5 & 6 & 7\end{array}$

6. Have resources to improve academic success

$1 \quad 2 \quad 3$

Please rate your level of agreement with the following statements:

7. Overall, I have been satisfied with business FYE

8. I intend to complete my degree at the University

$\begin{array}{llllllll}1 & 2 & 3 & 4 & 5 & 6 & 7\end{array}$

9. I intend to stay in the School of

Business at the University

$\begin{array}{llllllll}1 & 2 & 3 & 4 & 5 & 6 & 7\end{array}$

10. I like the curriculum better than other business school's

$\begin{array}{llllllll}1 & 2 & 3 & 4 & 5 & 6 & 7\end{array}$

$\begin{array}{llllllll}1 & 2 & 3 & 4 & 5 & 6 & 7\end{array}$




\section{$\underline{\text { NOTES }}$}

